\title{
COMPARATIVE STUDY OF RADIOLOGICAL AND FUNCTIONAL OUTCOME OF EXTRA ARTICULAR DISTAL RADIUS FRACTURE TREATED CONSERVATIVELY WITH RESPECT TO ITS POSITION OF IMMOBILIZATION
}

Gopal Prasad Gnawali ${ }^{1}$

\begin{abstract}
\section{INTRODUCTION}

Distal radius fracture is one of the common injury in orthopedic trauma. Traditionally, this fracture is being treated with closed reduction and immobilization in palmer flexion and ulnar deviation. This position of immobilization has been shown with poor functional result. So the aim of our study is to compare the radiological and functional outcome of distal radius fracture treated conservatively with respect to position of immobilization.
\end{abstract}

\section{MATERIAL AND METHODS}

Hundred patients, all above 20 years of age with distal radius fracture where treated with closed reduction and below elbow cast application. Patients were randomly allocated to dorsal and palmer flexed plaster cast application, fifty in dorsiflexion group and fifty in palmer flexion group. All patients were followed up at $2^{\text {nd }}$ week, $4^{\text {th }}$ week, $6^{\text {th }}$ week and $12^{\text {th }}$ weeks. Radiological parameters measured in every follow-up and functional parameters measured after removal of cast in last two follow up. The results were scored and compared by Demerit Scoring System of Saito. For comparison, $t$ test and Chi square test were used as necessary.

\section{RESULTS}

All fractures united. All individual movements of wrist were significantly better in the dorsiflexed immobilized group as compared with the palmerflexed immobilized group. Radiological parameters were also markedly better in the dorsiflexed group.

\section{CONCLUSION}

Both radiological and functional results of the extra articular distal radius fracture are better if the fracture immobilized in the dorsiflexed position after reduction rather than traditional palmer flexion position.

KEYWORDS Cast immobilization, dorsiflexion, palmer flexion, distal radius fracture, radiological outcome, functional outcome.

1. Consultant Orthopedic Surgeon, Department of Orthopedics, Lumbini Zonal Hospital, Rupandehi.

\author{
For Correspondence \\ Dr. Gopal Prasad Gnawali \\ Consultant Orthopedic Surgeon \\ Lumbini Zonal Hospital \\ Department of Orthopedics \\ Email: gnawaligopal100@yahoo.com
}




\section{INTRODUCTION}

Distal radius fracture is one of the most common injury in orthopedic practice accounting about one sixth of the all fracture treated in the emergency room. There is no consensus regarding the description of the condition, the appropriate treatment, or even the anticipated outcome. The treating concept of the distal radius fracture is being changed suggesting the operative treatment for complex intra-articular fractures. ${ }^{1}$

Reduction is not a problem but maintaining is. Residual disability after Colles' fractures reported as high as $90 \%{ }^{2 .}$ It is well accepted that restoration of anatomy and early mobilization ensures better results. Numerous studies have taken the amount of displacement into consideration but very few have done on the role of position of immobilization as a parameter for comparing radiological and functional outcome.

The present study was undertaken to evaluate the functional and radiological outcome of conservatively treated extraarticular fracture when the wrist was immobilized in DF or in PF.

\section{MATERIAL AND METHODS}

It was a comparative prospective study done in emergency department and Department of Orthopedic (OPD), Lumbini Zonal Hospital and Meditech International Hospital, Butwal from April 2015 to May 2017. An approval from institutional review board was taken. Written informed consent was taken from included patients. Total 100 patients with distal radius fracture were taken out of which 50 patients were allocated for DF group and 50 patients were allocated for PF group. Randomization of the cast type done by selection of patient alternatively while applying the cast either in DF or in PF of wrist so that every alternate patient will have different type of cast.

Inclusion criteria were closed displaced, extra articular, with or without fracture of ulnar styloid process. Exclusion criteria were age less than 20 years, intra-articular fracture, pathological fracture, open fracture, fracture with neurovascular compromise or with impending compartment syndrome (carpal tunnel syndrome), poly-trauma with head injury, failed closed reduction, more than $50 \%$ comminuted fracture, patient arrived after 7 days of trauma, associated fracture of ulna (except tip of ulnar styloid process) and carpal bones,suspected ligamentous injury around wrist and hand, fracture above $2.5 \mathrm{~cm}$ from distal articular surface of radius.

Fracture was reduced closed in emergency department or operating room under hematoma block regardless of the type of the cast to be applied. All reductions were done by the author with help of available assistant by appropriate maneuver. (traction, ulnar deviation and flexion at fracture site for Colles type of fracture and traction, ulnar deviation and extension at the fracture site for Smith type fracture).

Once fracture was reduced, it was immobilized by below elbow cast application with wrist either $15 \mathrm{deg}$ DF or $15 \mathrm{deg}$ $\mathrm{PF}$ according to randomization of cases. Image intensifier was not used. All patients were explained about the cast complications and send for check X-Ray for the acceptable reduction as per guideline.
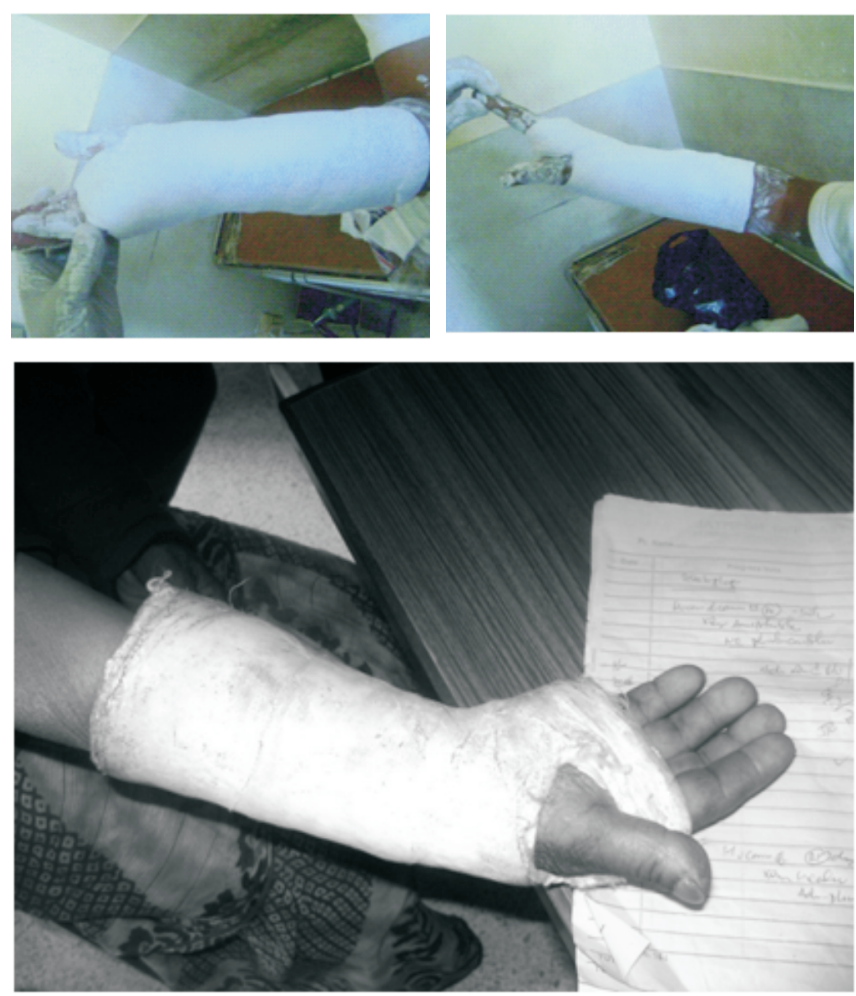

Fig $1(a, b, c)$. Plaster application method in the position of wrist dorsiflexion and palmerflexion.

The basic information like age, sex, address, injured side, mechanism of injury, hand dominance were all noted. Prereduction radiographic angles as well as post reduction angles were also noted with help of plastic scale and goniometer. Five follow up made for all cases which were next day of plaster application, first week, second week, sixth week and twelfth week. At each follow up lateral and AP radiograph of wrist was analyzed in OPD for acceptance. In first four follow ups, radiological parameter was measured. In last two follow ups clinical and radiological as well as functional parameter were measured. 
Radiological parameter, ${ }^{4,5,6,7,8}$ Radial tilt- 22-23 deg, range: $13-$ $33 \mathrm{deg}$, Palmer tilt- 11-12 deg, range:1-21 deg Ulnar variance $2 \mathrm{~mm}$ and range $: 2$ to $+2 \mathrm{~mm}$

At 6 weeks, plaster was removed after radiographic evaluation. Range of motion and grip strength was measured and recorded. Patients were sent to physiotherapy and advised to review at twelve weeks with wrist radiograph. Functional parameter included subjective evaluation, range of motion of wrist and grip strength measured at 6 th week and at 12 th week. Subjective evaluation was done by asking subjective questions regarding pain, disability, limitation of the motion and restriction of activity' and scored as demerits scoring system of Saito. ${ }^{9}$

Grip strength was measured at $6^{\text {th }}$ week after removal of plaster and at $12^{\text {th }}$ week after physiotherapy with the help of sphygmomanometer and compared with normal contra lateral hand. The cuff of the sphygmomanometer rolled and inflated up to $20 \mathrm{~mm}$ of $\mathrm{Hg}$ and patients were asked to squeeze as hard as he or she can. A normal hand should be able to achieve $200 \mathrm{~mm}$ of $\mathrm{Hg}$ or more ${ }^{10}$

Radiological and functional result of both groups were calculated using Satio's scoring system and adding all the points finally graded as follows Excellent- 0to3, Good- 4 to 9, Fair - 10 to 15 , and Poor - 16 to26. Both of DF and PF group were compared with each other on the above mentioned parameter.

Data was entered in Microsoft Excel. Data analysis was carried out using statistical package for social science, version 20 (SPSS ${ }^{\mathrm{TM}}$ Inc. Chicago, USA). Student T Test and Pearson Chi Square were done to compare mean of two groups. P value of less than 0.05 was considered statistically significant.

\section{RESULTS}

There were 126 patients who after initial assessment were found to be eligible for the study (66 patients in DF group and 60 patients in PF group). They were treated by closed reduction and plaster cast application out of them 20 patients lost follow up (13 patients in DF 7 in PF). Two patients did not give consent. Nine patients had unacceptable reduction (6 patients in DF group and 3 patients in PF group). They were retreated out of them 4 patients were excluded due to unacceptable reduction. (Three patients in DF group and one patient in PF group). They were treated by ORIF.

The mean age of the patients in the DF group was 49.88 years and the mean age of the patients in PF group was 52.74. There were 72 female and 28 male patients participating in study out of which 15 were male and 35 were female in DF group and 13 were male and 37 were female in PF group. There were 48 patients with fracture involving the left extremity and 52 patients with fracture involving the right side. Fall was the commonest mechanism of injury.

Radiological parameters

Table1. Radial tilt, palmer tilt and ulnar variance in successive follow up

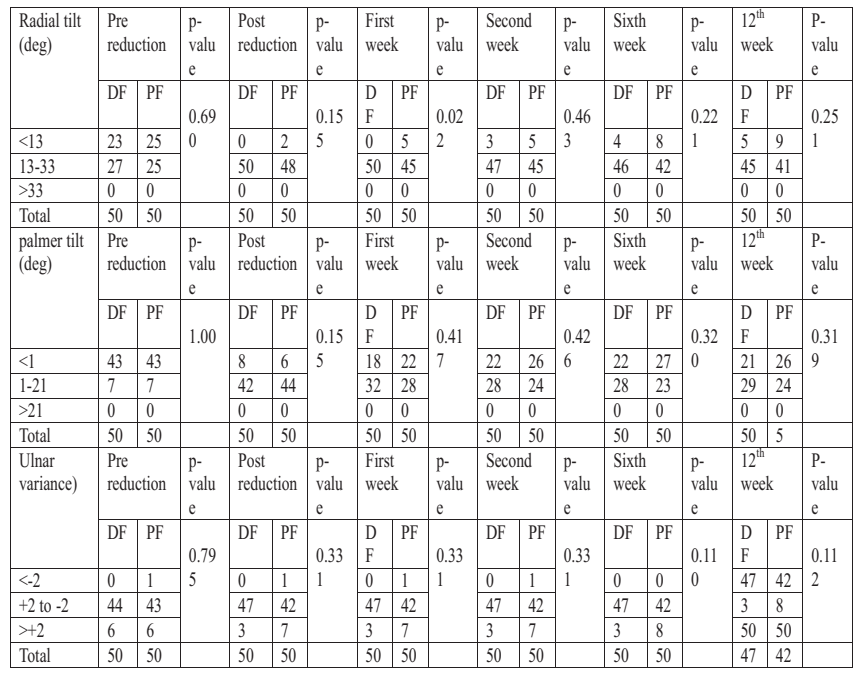

Table2. Mean radiological parameters with standard deviation at $6^{\text {th }}$ and $12^{\text {th }}$ weeks

\begin{tabular}{|c|c|c|c|c|c|c|}
\hline \multirow{2}{*}{$\begin{array}{l}\text { Radiological } \\
\text { parameter }\end{array}$} & \multicolumn{3}{|c|}{ SIX WEEKS } & \multicolumn{3}{|c|}{ TWELVE WEEKS } \\
\hline & \begin{tabular}{|l|} 
DF group \\
\end{tabular} & PF GROUP & PVALUE & DF group & PF GROUP & PVALUE \\
\hline Radial tilt & ..m & $18.22 \pm 3.400$ & 0.495 & $18.56 \pm 3.406$ & $18.22 \pm 3.518$ & 0.625 \\
\hline Palmer tilt & $4.20 \pm 5.897$ & $2.14 \pm 8.084$ & 0.149 & $18.56 \pm 3.406$ & $18.22 \pm 3.518$ & 0.625 \\
\hline \begin{tabular}{|l|} 
Ulnar \\
variance
\end{tabular} & $1.66 \pm 0.939$ & $1.46 \pm 1.468$ & 0.387 & $1.66 \pm 0.939$ & \begin{tabular}{|l|l}
$1.46 \pm 1.358$ \\
\end{tabular} & 0.394 \\
\hline
\end{tabular}

Table 3. Mean range of motion of wrist compared at $6^{\text {th }}$ at $12^{\text {th }}$ weeks

\begin{tabular}{|l|l|l|l|l|l|l|}
\hline \multirow{2}{*}{$\begin{array}{l}\text { Mean ROM } \\
(\mathrm{deg})\end{array}$} & \multicolumn{4}{|l|}{ SIX WEEKS } & \multicolumn{2}{l|}{ TWELVE WEEKS } \\
\cline { 2 - 7 } & DF group & $\begin{array}{l}\text { PF } \\
\text { GROUP }\end{array}$ & P VALUE & DF group & $\begin{array}{l}\text { PF } \\
\text { GROUP }\end{array}$ & P VALUE \\
\hline DF & 32.44 & 18.20 & 0.0001 & 46.80 & 38.70 & 0.0001 \\
\hline PF & 23.70 & 25.7 & 0.024 & 39.30 & 39.30 & 1 \\
\hline RD & 16.32 & 12.10 & 0.003 & 24.70 & 20.70 & 0.0001 \\
\hline UD & 25.10 & 21.3 & 0.009 & 30.50 & 26.90 & 0.001 \\
\hline Supination & 46.80 & 43 & 0.03 & 57.50 & 52.70 & .0001 \\
\hline Pronation & 44.80 & 48.20 & 0.011 & 53.80 & 55.00 & 0.006 \\
\hline
\end{tabular}

Table 4 . Grip strength comparison between two group at 6 weeks and 12 weeks

\begin{tabular}{|c|c|c|c|c|c|c|}
\hline Grip strength & \multicolumn{2}{|c|}{ 6wks } & & \multicolumn{2}{|c|}{$12 \mathrm{wks}$} & \multirow{5}{*}{$\begin{array}{l}\text { P VALUE } \\
0.0009\end{array}$} \\
\hline & DF & $\mathrm{PF}$ & \multirow{4}{*}{$\begin{array}{l}\text { P VALUE } \\
0.001\end{array}$} & DF & PF & \\
\hline NORMAL & 5 & 4 & & 44 & 33 & \\
\hline Loss of $1 / 2$ power & 44 & 29 & & 6 & 16 & \\
\hline Loss of $2 / 3$ power & 1 & 17 & & 0 & 1 & \\
\hline
\end{tabular}


Table 5. Comparison of subjective feeling in two groups at $6^{\text {th }}$ weeks and 12 th weeks

\begin{tabular}{|c|c|c|c|c|c|c|}
\hline Subjective & \multicolumn{2}{|c|}{$6 \mathrm{wks}$} & & \multicolumn{2}{|c|}{$12 \mathrm{wks}$} & \\
\hline & DF & $\mathrm{PF}$ & \multirow{5}{*}{$\begin{array}{l}\text { P VALUE } \\
0.001\end{array}$} & DF & $\mathrm{PF}$ & \multirow{5}{*}{$\begin{array}{l}\text { P VALUE } \\
0.0001\end{array}$} \\
\hline Excellent & 0 & 0 & & 30 & 7 & \\
\hline Good & 29 & 7 & & 17 & 36 & \\
\hline Fair & 20 & 33 & & 3 & 6 & \\
\hline Poor & 1 & 10 & & 0 & 1 & \\
\hline
\end{tabular}

Table 6. Comparison of finger stiffness at sixth weeks and 12weeks

\begin{tabular}{|c|c|c|c|c|c|c|}
\hline Finger & \multicolumn{2}{|c|}{ 6wks } & & \multicolumn{2}{|c|}{$12 \mathrm{wks}$} & \\
\hline & DF & $\mathrm{PF}$ & \multirow{4}{*}{$\begin{array}{l}\text { P VALUE } \\
0.002\end{array}$} & DF & $\mathrm{PF}$ & \multirow{4}{*}{$\begin{array}{l}\text { P VALUE } \\
0.0012\end{array}$} \\
\hline None & 30 & 7 & & 45 & 35 & \\
\hline $\begin{array}{l}\text { None } \\
\text { disabling }\end{array}$ & 17 & 36 & & 5 & 14 & \\
\hline Disabling & 3 & 6 & & 0 & 01 & \\
\hline
\end{tabular}

Table7. Comparison of Saito score at 6 weeks and 12 weeks

\begin{tabular}{|c|c|c|c|c|c|c|}
\hline Saito score & \multicolumn{2}{|c|}{ 6wks } & & \multicolumn{2}{|c|}{$12 \mathrm{wks}$} & \\
\hline & DF & $\mathrm{PF}$ & \multirow{5}{*}{$\begin{array}{l}\text { P VALUE } \\
0.001\end{array}$} & DF & $\mathrm{PF}$ & \multirow{5}{*}{$\begin{array}{l}\text { P VALUE } \\
0.0001\end{array}$} \\
\hline Excellent & 2 & 2 & & 42 & 14 & \\
\hline Good & 28 & 11 & & 8 & 34 & \\
\hline Fair & 20 & 33 & & 0 & 02 & \\
\hline Poor & 0 & 4 & & 0 & 0 & \\
\hline
\end{tabular}

\section{DISCUSSION}

There is still no clear agreement regarding the best position of immobilization for distal radius fracture. ${ }^{11}$ Regarding pronation and supination different views are claimed to be effective. Sermentio ${ }^{12,13}$ advised for supination of the forearm to reduce the deforming force of brachioradialis while Wahlstrom ${ }^{14}$ recommended the pronation of the forearm to neutralize the deforming force of pronator quadrates.

Traditionally, the distal radius fracture is being treated in palmer flexion and ulnar deviation as advised by the John Charnley $^{15}$. He says that this position dorsal periostel hinge provide the stability. But, effectiveness of this method is being challenged in recent time for the increase incidence of redisplacement, poor hand function and acute or chronic carpal tunnel syndrome. ${ }^{16}$ The concept of positioning the wrist in dorsiflexion was brought by the Zuppinger's recommendation ${ }^{16,17}$. He suggested changing the position of wrist from slight palmer flexion at the time reduction to neutral to slight extension with maintaining ulnar deviation after two weeks of initial reduction.

This study shows few similarities with the study done by Gupta A in $1991 .{ }^{18}$ He applied plaster cast on 204 patients with displaced distal radius fracture in different position of wrist allocated randomly in three groups: Palmer flexion, neutral or dorsiflexion. They reported that in distal radius fracture without communition, the position of the wrist made no significance difference regarding its later displacement. In comminuted fractures, best anatomical results were found in fractures treated with in dorsiflexion. In all fractures, best functional results found in dorsiflexion group.

Our study is more or less similar to the study done by Sunil Rajan et al in $2006^{19}$. They treated 26 distal radius fractures by plaster application. Position of wrist was allocated randomly in either dorsiflexion or palmer flexion. They did six-month follow up which shows both anatomical and functional results were superior in dorsiflexion group which was obtained by Demerit Scoring System of Saito.

A study done by Gupta $\mathrm{A}^{18}$ also correlates the better result in dorsiflexion group with the bio mechanics of wrist joint with fracture reduction. In PF the dorsal carpal ligament is taut, but cannot stabilize the

fracture because of its lack of an attachment to distal carpal row. The deforming forces and the potential displacement of the fracture are parallel, in the same direction. In DF, the volar ligaments are taut and tend to pull the fracture fragment anteriorly. The deforming forces act at an angle which tends to reduce the displacement of the fracture. ${ }^{18-21}$

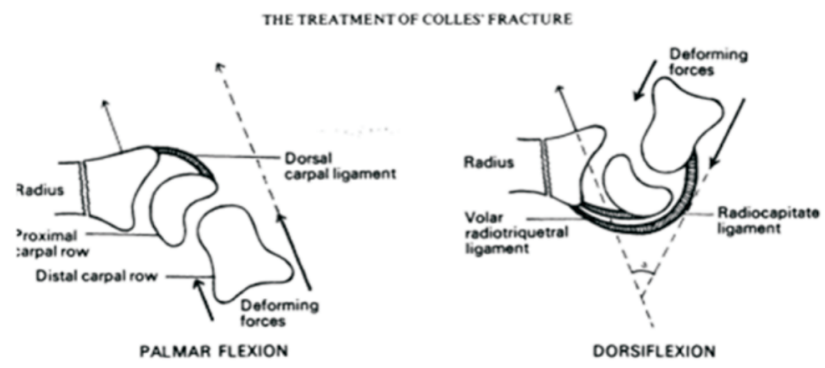

Fig 2. Relation of stability of fracture and attachment of dorsal and volar carpal ligament.

The fracture in reduction easily collapse in straight tube and single curve uniform tube which is formed in palmer flexed position of the wrist. In $\mathrm{S}$ shaped double curve tube, the chances of collapse is less, so in the dorsiflexed position of the wrist $^{18}$.



Fig 3.Straight and curved tube phenomenon in relation with fracture collapse. 
In this study, we compared the functional and radiological results of the extra articular fracture of the lower end of the radius treated conservatively in two groups, one with wrist immobilized in DF and other in PF. We found the individual movements of DF, PF, supination, pronation, ulnar and radial deviation as well as total range of movement are significantly better when the wrist is immobilized in the dorsiflexion as concluded by Gupta A. ${ }^{18}$ Further, grip strength recovery and subjective assessment of the pain, disability and limitation of the movement was also better and faster in dorsiflexion immobilized group.

Radiological parameters as measured by ulnar variance, palmer tilt and radial tilt were not seen differ much at the first follow up between DF and PF wrist immobilized patients. However, maintenance of the parameters in successive follow up was found to be markedly better in DF group as compared to the PF group. The residual deformity seemed to be greater in PF group. Thus, radial tilt, Palmer tilt and ulnar variance all were found to be significantly well maintained in the DF immobilized group as compared to the PF group throughout the follow up stating that later has increased chance of redisplacement.

Since, the wrist extension is the optimal position for hand function and rehabilitation of the finger, along with the fact that PF is associated with the higher rate of fracture displacement, Gupta concluded that flexion at the fracture site is important to make use of the dorsal periosteal hinge but the flexed position need not be maintained at the wrist joint.

It is concluded that better results in DF immobilized wrist and because DF is needed for rehabilitation of fingers and the optimal functional position of for the hand is wrist in extension. Thus in conservatively treated extra articular fracture of the lower end of radius. Flexion should be at the fracture site to make use of the periosteal hinge but the wrist should be immobilized in position of slight extension. ${ }^{15,20}$

One of the drawbacks of this study is less number of patients in the study. Another drawback is taking limited the radiological measurements as described in previous articles. Measurements of range of motion were also done by goniometer. This may have influenced some results but this is what we usually do in our setting. And in developing country like ours, we have to depend on easily available instruments on many occasions. Grip strength measured with the help of sphygmomanometer which may influence the outcome.

We did not measure others important radiological parameters such as radial length, dorsal tilt of distal fragment, which do have influence in the subsequent of radiological and functional outcome.

\section{CONCLUSION}

It is concluded that better results in dorsiflexion immobilized wrist because dorsiflexion is needed for the rehabilitation of fingers, and the optimal functional position for hand is wrist in extension. So, in conservative treatment of distal radius fracture, flexion should be at the fracture side to make advantage of periosteal hinge but the wrist should be immobilized in position of slight extension. ${ }^{13,17}$

Both radiological and functional results of the extra articular distal radius fracture are better if the fracture immobilized in the dorsiflexed position after reduction rather than traditional palmer flexion position.

\section{CONFLICT OF INTEREST}

None declared.

\section{ACKNOWLEDGEMENTS}

I would also like to express my profound appreciation and gratitude to my colleges for the completion of study. Above all I deeply appreciate the cooperation of my patients enrolled in the study without them this would not have been possible.

\section{FINANCIAL AIDS}

No funds were available.

\section{REFERENCES}

1. Goyrand G, Memoire sur les fractures de I; extremity inferieure du radius qui simulent les luxation du poignet. Gaz.Med 1832;3:664-7.

2. Golden GN. Treatment and prognosis of Colles fracture. Lancet 1963;1:511-4.

3. Graham TJ: Surgical correction of malunited fractures of the distal radius, J Am Acad Orthop Surg 5:270, 1997.

4. Metz VM,Gilula IA. Imaging technique for distal radius fractures and related injuries. Orthop Clin North Am 1993; 24:217-28.

5. Fernandez DL, Jupiter JB.Fracture of distal radius-A practical approach to management. First ed. New York: Springer and Verlag; 1996.p.54-65.

6. Pool C.Colles Fracture: A prospective of treatment. J Bone Joint Surg Br 1973;18:588-91.

7. Tsukazaki T,Takagi K, Lwasaki K.Poor correlation between functional result and radiographic findings in colles fracture. J Hand Surj Br 1993;18:588-91. 
8. Kernezis IA,Panaggiotopolus E,Tyllianakis Megas P, Lambiris E. Correlation between radiological parameters and patient rated wrist dysfunction following fracture of the distal radius. Injury 2005;36:1435-9.

9. Young BT, Rayan GM. Outcome following non operative treatment of displaced distal radius fractures in low demand patients older than sixty years. J Hand Surg Am 2000; 25 $: 19-28$.

10. Petersen P, Petric M, Connor H, Conklin D. Grip strength and hand dominance: Challanging the $10 \%$ rule. Am J Occup Ther 1989;43:444-7.

11. Fernandez DL, Jupitar JB.Fracture of the distal radius. A practical approach to management.Firsted. New York: Springer and Verlag:1996.p.54-65.

12. Sermantio A, Latta LL.The evolution of functional bracing of fracture. J Bone and Joint Surg Br 1995;88:141-8.

13. Sarmentio A,Zagorski JB,Sinclair WF. Functional bracing of Colles fracture: A prospective of immobilization in supination vs pronation. Clin Orthop Relat Res 1980;146 :175-83.

14. Wahlstrom O. Treatment of colles fracture. Acta Orthop Scand $1982 ; 53: 225-8$.
15. Charnley J. The Colles fracture. The Closed treatment of common fracture $4^{\text {th }}$ edition vol 4,1999.p. 128-42.

16. Fernandez DL, Jupitar JB.Fracture of the distal radius. A practical approach to management.First ed. New York: Springer and Verlag: 1996.p.23-52

17. Bohlar L. The treatment of facture, $3^{\text {rd }}$ ed . New York: Grune and Stratton:1932. P .90-6.

18. Gupta A. The treatment of colles fracture Immobilization with the wrist in dorsiflection. J Bone Joint Surg Br $1991 ; 73$ :312-5.

19. Sunil Rajan, Saurabh jain, A Roy, P Vargava, Radiological and functional outcome in extra-articular fracture in lower in of radius treated conservatively with respect to position of immobilization, Indian journal of orthopedic2008;42:201-8.

20. Kernezis IA,Panaglotopoulos E, Tyllianakis M, Megas P, Lambiris E. Correlation between radiological and parameters and patients rated wrist dysfunction following fracture of the distal radius. Injury 2005;36:1435-9. Szabzo RM. Extra articular fracture of the distal radius. Orthop Clin North Am $1993 ; 24: 229-37$ 